\title{
Editorial
}

\section{Implementing Real-Time Data Suicide Surveillance Systems}

\author{
Anna Baran ${ }^{1,2}$, Rebekka Gerstner ${ }^{3}$, \\ Michiko Ueda ${ }^{4}$, and Agnieszka Gmitrowicz ${ }^{1,5}$ \\ 'Working Group on Prevention of Suicide and Depression at the \\ Public Health Council of the Ministry of Health, Warsaw, Poland \\ 2Department of Psychiatry, Blekinge Hospital, Karlshamn, Sweden \\ ${ }^{3}$ Ministry of Public Health, Undersecretary of Health Services, Quito, Ecuador \\ ${ }^{4}$ Faculty of Political Science and Economics, Waseda University, Tokyo, Japan \\ ${ }^{5}$ Department of Child \& Adolescent Psychiatry, Medical University of Lodz, Poland
}

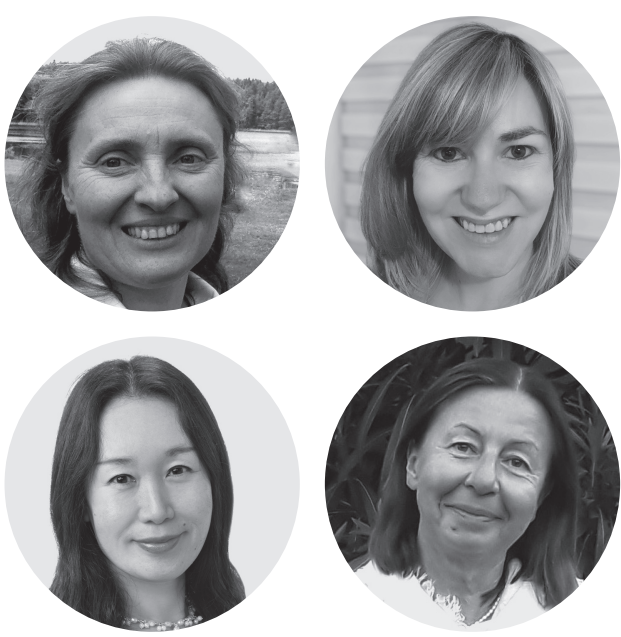

In this editorial, we would like to inspire policy makers to support the real-time monitoring of suicide. Using real-time data to understand the spatiotemporal variability of suicides will allow policy makers evaluate interventions they have invested in and enable them to intervene in a timely manner in situations when an increase in suicides in any region or among any group in the community might be anticipated because of particular circumstances (e.g., quarantine, unemployment and economic crisis, or inappropriate media reporting). Real-time monitoring allows suspicions to be confirmed or rejected, which in turn gives hope for the development of resilience and coping or avoids the spread of inaccurate rumors. Networking and exchange of know-how can help in the development of real-time suicide surveillance systems. Our editorial begins by making the case for real-time surveillance of suicide and then provides examples of systems in three countries: Ecuador, Poland, and Japan.

\section{The Case for Real-Time Surveillance of Suicide}

Reducing the global suicide mortality rate by one third by 2030 is an indicator and a target in the United Nations (UN) Sustainable Development Goals (SDGs) and in the Comprehensive Mental Health Action Plan 2013-2030 of the World Health Organization (WHO). The WHO's Thirteenth General Programme of Work 2019-2023 includes a reduction in suicide of $15 \%$ by 2023 . Up-to-date data on suicide rates is needed to enable the surveillance, monitoring, and evaluation that are necessary to determine whether these targets are being reached.

Importantly, data from established suicide surveillance systems (civil registration and vital statistics systems [CRVSs], health and police records, verbal autopsy, and population-based surveys) will be critical for shaping and evaluating interventions, such as those proposed through the WHO's LIVE LIFE approach (WHO, 2021): "Sustained surveillance should be included as a priority and should be set up before or at the beginning of LIVE LIFE implementation as it will allow countries to evaluate the effectiveness of the interventions implemented" (p. 47). To be maximally useful, data should be disaggregated at a minimum by gender, age, and method (WHO, 2021). The WHO also recommends that in countries where comprehensive CRVSs and other surveillance systems are established, the data quality, coverage, timeliness, and costs of the surveillance system should be monitored (WHO, 2021). Monitoring these elements of national data on suicides is an essential component of the development of an integrated data collection system in national prevention programs (Arensman, 2017).

Having access to real-time data on suicides will have significant benefits. The timeliness of these data will inform evaluation exercises, allowing interventions to be modified or adapted as they are rolled out to improve their effectiveness. In addition, these data will permit quick responses to emerging situations which may be likely to impact suicide rates. Some of the surveillance systems mentioned above are more amenable to collecting real-time data than oth- 
ers. For example, police records often form an immediate part of the process of investigating a suicide. As a result, systems that use data from these sources are often timely. By contrast, CRVSs tend to rely on full, and often lengthy, investigations by coroners or medical examiners. This means that although these systems are often regarded as the source of truth for national suicide statistics, they tend to involve data lags that make them less useful for evaluation and response purposes.

Real-time suicide reporting has key implications for policy development, research funding, and the evaluation of preventive and intervention programs (Värnik et al., 2012). It can be used to evaluate interventions and to analyze the potential impact of environmental or contextual changes (e.g., the COVID-19 pandemic, unemployment shocks, changes in migration patterns, innovations in healthcare and social care systems, spikes in inappropriate media reporting of suicide). Surveillance systems help to highlight trends in suicidal behavior, subpopulation groups at risk, clusters of cases, or the emergence of new or potentially "contagious" methods of suicide that would need prompt action (Thomas, Chang \& Gunnell, 2011). The real-time surveillance of suicides by ingesting pesticides, the training of medical teams to manage the effects of pesticide poisoning, and the ban of pesticides from agriculture in 2008-2011 contributed to the reduction in Sri Lanka in total numbers and in pesticide suicide numbers in particular (Knipe et al., 2017).

\section{A Real-Time Suicide Data Monitoring System in Ecuador}

\section{Description}

The Ministry of Public Health in Ecuador does not uniformly collect national suicide attempt or suicide data, but data are available from various sources.

\section{Police Records of Suicides}

In Ecuador, suicide is classified as a violent death. Therefore, the national police, specifically the National Directorate of Crimes Against Life, Violent Deaths, Disappearances, Extortion, and Kidnapping (DINASED), must be present for the removal of the body. The police investigates, records, and systematizes the information in the David $20 \nmid 2$ computer system for deaths with external causes, mainly homicides and suicides. The variables collected via this system are outlined in Table 1. This information is later complemented with the result of the autopsy performed by the National Legal Medicine and Forensic Science Service.
While the police obtains its information directly from the scene of death and later validates this with legal reports, the Ecuadorian Institute of Statistics and Census (INEC) cross-checks the official death registration forms with the registers from the police and uses only validated data. Although there is a small difference of $10 \%$ in the numbers of suicides registered by the police and the INEC, the general trends of the police data are very useful for real-time surveillance.

The police indicates that the registration and visualization of homicide data in real time in the David 20;2 computer system may be one of the main reasons for the decreasing rate of violent deaths, which reached its lowest point of the last 35 years in 2015 (Torresano-Melo, Calles-López, \& García-Mejía, 2018). Hence, real-time surveillance of suicide could be a helpful tool as well, coupled with rapid intervention after particular events or in particular locations.

\section{Toxicological Information and Advice Center}

The Toxicological Information and Advice Center (CIATOX) is a specialized service which provides advice to healthcare personnel for the treatment of poisoning. In 2020, CIATOX received and registered data from approximately five thousand calls, half of them related to intentional poisoning. Most people who had self-poisoned were rescued and survived the suicide attempt.

\section{Example of Benefit: Tracking Suicides During COVID-19}

Ecuador is one of the 10 countries worldwide which has been most affected by the COVID-19 pandemic in terms of deaths, with COVID-19 accounting for an excess death rate of 319 per 100,000 (The Economist, 2021). In April 2020, the coastal city of Guayaquil suffered one of the highest death tolls globally. It was 15 times higher than expected for this month (León-Cabrera \& Kurmanaev, 2020). Following this rise in excess deaths, the Ministry of Public Health feared that there might be an increase in suicides in response to the difficult socioeconomic and psychological situation brought about by the pandemic. We therefore conducted a real-time analysis of the impact of COVID-19 on suicide rates, using police records and CIATOX.

During the pandemic, between March and August 2020 , calls related to intentional poisonings decreased by $36 \%$ compared to 2019, while between September and December 2020 the difference was only $-7 \%$. The police reports presented fewer pronounced differences between 2019 and 2020 than CIATOX, but trends were similar. Therefore, CIATOX registers can give a rough approxima- 
tion of suicide trends, and it is a database easily available to the Ministry of Health.

The Ministry of Public Health used data from these surveillance systems in the development of a national plan for suicide prevention, which should be finished by December 2021 , and in the planning of the following specific prevention activities:

- Training of primary care professionals, health promotion agents, local community actors, and mental health professionals in the manual Training for Community Caregivers in Suicide Prevention (MSP, 2019) across cities with a high incidence of suicide.

- Training of first responders in towns with a high incidence of suicide in public places such as bridges, and working on a protocol for intervening to prevent suicide attempts for nonspecialists in mental health.

- Guidelines for care and follow-up of patients with suicide attempts within public health services, using current data on training courses.

In countries with limited economic, human, and technological resources, it is particularly important to initiate actions that require fewer resources and are feasible to carry out. In Ecuador, further work is needed, but the first steps have been taken to raise awareness of the problem and to gradually move toward the implementation of the national plan for suicide prevention, using real-time data for decision making. In Ecuador, the COVID-19 pandemic has served as an impetus to increase awareness and to strengthen actions to prevent suicide.

The greatest current challenge is to strengthen mental health services by increasing the number of mental health professionals in the country, creating community mental health centers, extending professional training in order to increase the number of specialized human resources and intervene in a more timely manner in places with an increase in suicides.

\section{A Real-Time Suicide Data Monitoring System in Japan}

\section{Description}

There are two types of data on suicide deaths in Japan. One is based on death certificates issued by physicians, which are subsequently reported in the vital statistics of the Ministry of Health, Labour, and Welfare (MHLW). However, the data have a delay of at least 6 months before provisional data are released. The second type of data, which is the focus of this section, are the suicide statistics compiled by the National Police Agency (NPA). Both the vital statistics and the NPA's suicide statistics report only suicide deaths attempted suicides are not covered.

In Japan, all suspected suicides are investigated by the police. Once the police determine the cause of a particular death to be suicide, they record the case in their suicide statistics system. The items recorded in the data are shown in Table 1. However, not all items and categories are included in the publicly available data due to the sensitive nature of the information. For the same reason, the individual-level data are not released to the public, including academic researchers. Currently, the NPA is in the process of revising the items and categories (such as occupation categories) reported in the dataset.

Each month, the individual-level data are aggregated to the municipality and prefecture level before being released to the public by the NPA (https://www.npa.go.jp/publica tions/statistics/safetylife/jisatsu.html) and the Ministry of Health, Labour, and Welfare (https://www.mhlw.go.jp/stf/ seisakunitsuite/bunya/hukushi_kaigo/seikatsuhogo/jisat su/jisatsu_new.html). The rapid-release data are published in the first half of the following month, which makes early monitoring by stakeholders possible. The data are continuously updated until the NPA finalizes the data of the calendar year in March of the subsequent year. No further updates are made after the release of the finalized data.

The NPA's data may be considered accurate. Although the vital statistics and the NPA's suicide statistics come from two independent sources, the numbers reported in these two datasets are highly correlated. Based on the data on the total number of suicides between 1978 and 2019, the correlation coefficient is $0.996(N=42)$.

\section{Example of Benefit: Tracking Suicides During COVID-19}

No event has better demonstrated the benefits of maintaining real-time data than the COVID-19 pandemic. In spring 2020, suicide prevention experts started to notice a decline in the number of suicides during the first state of emergency (April-May 2020), which may have reflected a decade-long declining trend in the country. As early as June 2020, experts started to express their concern in the media for a potential increase in subsequent months. By summer 2020, the NPA data made it clear that the trend had indeed reversed and that relatively young women were the most vulnerable group. By fall 2020, the media had started to cover stories on the increase in suicide deaths, and the Japanese government and other organizations began to take swift action to mitigate the impact of the pandemic on people's mental health and employment status. Such actions included the expansion of suicide prevention 
helpline services, enhanced assistance for single parents and people experiencing intimate partner violence, as well as financial and other types of assistance for those who had lost their job due to the pandemic. In addition, the Japan Suicide Countermeasures Promotion Center, an organization commissioned by the Ministry of Health, Labour, and Welfare, conducted a preliminary analysis using NPA's daily data to demonstrate that the number of suicides had immediately increased after the media reporting on a young actor's suicide in July 2020. Based on the findings, the center and the MHLW requested the media in Japan to use responsible reporting following celebrity suicides. These actions would not have been possible without the rapid-release data by the NPA.

\section{A Real-Time Suicide Data Monitoring System in Poland}

\section{Description}

In Poland, data on suicides are collected by Statistics Poland (Główny Urząd Statystyczny [GUS]) and the police headquarters (Komenda Główna Policji [KGP]). Only the data gathered by the police headquarters are available in real-time; they are released one month after the occurrence of a suicide, whereas the data from Statistics Poland are not available until 12-14 months later.

The police headquarters data include data on suicides and suicide attempts. They are limited, however, to data from suicides and suicide attempts where the police were called to the event. They do not include information from, for example, prisons and military units, and they do not contain complete information from hospital emergency rooms. Police provide data via a form known as KSIP-10. The items on the KSIP-10 form are given in Table 1.

Statistics Poland, on the other hand, only collects data on deaths and their causes (including suicides) obtained from death certificates. Therefore, the data are expected to include more cases of overdoses than the police headquarters data. However, if someone dies of complications from an overdose a few weeks later, this death may not necessarily be classified as a suicide. In some cases, doctors may report such deaths as being due to organ failure (e.g., liver or kidney failure). Some suicides associated with traffic may be classified as traffic accidents. Until 2013, there was a large discrepancy between the number of suicides in Statistics Poland data and police headquarters data. In 2009, Statistics Poland recorded 32\% more suicides than the police headquarters (Rosa, 2012). Since 2014, police headquarters have registered more suicides than Statistics
Poland. Nevertheless, the trends in suicides registered by Statistics Poland followed the trends of suicides registered by the police headquarters between 2000 and 2019, except for 2012 when the police headquarters changed their way of registering of suicides.

Until 2012, suicide data were collected by the police headquarters based on the form called Report of Suicides, which was entered into the system after the completion of the screening procedure, pursuant to Art. 308 of the Code of Criminal Procedure or preparatory proceedings. Since 2013, the data are entered into the KSIP-10, immediately after the event, when it is established that a suicide took place. The system freezes the data after 1 month, allowing for modification of cases where it is established at a later stage of the proceedings that there was no suicide/suicide attempt.

The Working Group on the Prevention of Suicide and Depression was appointed by Resolution No. 32016 of the Public Health Council to support the implementation of the National Health Program 2016-2020. The working group's work included the improvement of the registration of suicidal behaviors. The Report on Suicidal Behaviors - Suicides and Suicide Attempts (KSIP-10), published in 2017, outlines the most significant changes to the police suicide surveillance system (https://statystyka.policja.pl/st/wybrane-stat ystyki/zamachy-samobojcze). These included separation of suicides from suicide attempts, changes in nomenclature (e.g., from "suicide attack" [zamach samobójczy] to "suicide" [samobójstwo]), and the exclusion of some categories and the inclusion of others. Coordinators in every county were educated on how to fill in the KSIP-10 and then they educated police officers.

In May 2021, a task group for monitoring the epidemiology of suicidal behavior and social attitudes was established to further develop the national surveillance systems of suicidal behaviors. A new Polish program for suicide prevention was included for the first time in the National Health Program for 2021-2025 (adopted on March 30, 2021, by the Council of Ministers). One of the program's tasks is the development of a new monitoring system for suicide and suicide attempts combining different resources.

\section{Example of Benefit: Monitoring Suicides Following Media Reporting of Suicide}

The reporting of celebrity suicide may lead to an increased suicide rate of $8-18 \%$ in the following 1-2 months and to an increase of $18-44 \%$ of suicides by the same method where information on the method of suicide had been provided (Niederkrotenthaler et al., 2020). Polish media guidelines were introduced in 2018 (Baran et al., 2018), 
accompanied by conferences and workshops for media professionals. The outcome was that information about helplines was more commonly included in stories about suicide. However, it is still the case that media reports often discuss increases in suicide, catastrophizing the situation, and using it in political disputes in a way that can lead to subsequent suicidal acts. The information about the decrease in numbers of suicides garners much less interest. The fact that in 2018 the suicide rate in Poland was at the lowest level since 1989 attracted almost no media attention.

Thanks to the real-time monitoring system of the police headquarters in Poland, it is possible to know the number of suicides, split by gender and age groups, with just a onemonth lag. This makes it possible to monitor suicides occurring after a given media report and to present this information to editors and journalists.

As an example, on February 3, 2020, an article about a 14-year-old boy with the title Love in the Time of Plague was published at www.onet.pl (Schwertner, 2020). This article starts with the following sentence: "He still managed to find the time to sit his eight-grade exam, and even got through with a score of 98 percent. He shared the good news with his mum and then went straight from school to throw himself in front of a metro train."

There were 14 suicides among those aged under 18 in February 2020, compared to two in 2018 and five in 2019 in the same month. In 2021, the figure had dropped back to five. An increase could also be observed in the annual data. The following numbers were presented at the Second Suicidology Congress, taking place in Lodz, Poland, on November 19 and 20, 2020: 92 deaths in 2018, 94 in 2019, and 107 in 2020 (Baran, 2020). The timely presentation of these figures to relevant media organizations led to the modification of the original article, introducing trigger warnings and phone numbers of suicide crisis lines in all European countries. It also meant that it became more difficult to access the graphics.

Of course, it is difficult to establish a direct causal relationship between the publication of the article and the suicide rate observed in February 2020. Although suicide is a tragic and significant public health problem, the absolute numbers of suicide are, fortunately, low. This means that the spike in suicides by young people in February may have been the result of monthly fluctuations or other causes. For example, on February 4, 2020, a nationwide social campaign called Disappearing Children was launched in Poland, which attracted considerable attention, not all of which was appropriate. Nonetheless, the fact that real-time suicide data were available allowed us to rapidly identify an apparent spike in suicides and enabled us to highlight this with media organizations and guide appropriate actions.
The ongoing monitoring of how suicides are presented in the context of media reports has led to an innovative online educational program for journalists and media professionals in Poland. This program will be launched for the first time during 2022 as part of the international grant ELLIPSE (E-Lifelong Learning in Prevention of Suicide in Europe) at the Warsaw University (www.e-llipse.com). We hope that it will help improve the quality of media reporting.

\section{Summary of Item Gathered by the Real-Time Surveillance in Ecuador, Japan, and Poland}

Table 1 summarizes the data collected by the above realtime suicide surveillance systems.

\section{Potential Advantages of Real-Time Access to Suicide Data}

The examples of the benefits of real-time suicide surveillance systems are just that - examples. But there are many potential advantages. These systems allow us to:

- Observe much more rapidly the potential influence of situational, environmental, and sociocultural factors on the suicides in the different age/sex groups;

- Identify clusters of suicides and respond to them in a timely fashion;

- Identify public places which may be of particular concern as sites where suicides are occurring, and intervene;

- Provide current evidence on patterns of suicide that may quell public fears (e.g., fears that there may be sudden and dramatic increases in suicide rates in the early months of pandemic (Pirkis et al., 2021);

- Offer fast feedback to those who are in the business of communicating about suicide, so that they are equipped with the most up-to-date information and ensure that their messaging is safe and does not cause harm;

- Develop measures to mitigate newly discovered potential risk factors in order to increase resilience;

- Evaluate suicide prevention interventions in a way that ensures that they can be modified during their roll-out, if changes are needed; and

- Stimulate research using real-time data. 
Table 1: Data collected in real-time suicide surveillance systems in Ecuador, Japan and Poland

\begin{tabular}{|c|c|c|c|}
\hline Information gathered by police & Ecuador & Japan & Poland \\
\hline Names and surnames & $x$ & - & $x$ \\
\hline Date and place of birth & - & - & $x$ \\
\hline Residential address & - & $x$ & - \\
\hline Gender & $x$ & $x$ & $x$ \\
\hline Sexual orientation & $x$ & - & - \\
\hline Ethnicity & $x$ & - & - \\
\hline Nationality & $x$ & - & - \\
\hline Marital status & $x$ & - & $x$ \\
\hline Cohabitants & - & $x$ & - \\
\hline Education & $x$ & - & $x$ \\
\hline Work/education & $x$ & - & $x$ \\
\hline Occupation & - & $x$ & - \\
\hline Source of income & - & - & $x$ \\
\hline Health status - physical illness, handicap, psychiatric treatment, alcohol/drug abuse & $\begin{array}{c}\mathrm{X} \\
\text { (only handicap) }\end{array}$ & - & $x$ \\
\hline $\begin{array}{l}\text { Contact with the police, healthcare institution, social care institution, crisis center, } \\
\text { church in the last month before suicide }\end{array}$ & - & - & $x$ \\
\hline Place of suicide/suicide attempt & $x$ & $x$ & $x$ \\
\hline Date and time of suicide/suicide attempt & $x$ & $x$ & $x$ \\
\hline Result of suicide attempt (suicide or suicide attempt) & - & - & $x$ \\
\hline Method of suicide/suicide attempt & $x$ & $x$ & $x$ \\
\hline Probable cause of suicide/suicide attempt & $x$ & $x$ & $x$ \\
\hline Method of determination the cause of suicide/suicide attempt & - & - & $x$ \\
\hline Information on the medical assistance provided & - & - & $x$ \\
\hline Number of previous suicide attempts & - & - & $x$ \\
\hline Under the influence of alcohol or other intoxicants & $x$ & - & $x$ \\
\hline
\end{tabular}

\section{Conclusion}

Real-time suicide data may act as a barometer, showing immediate changes in the number of suicides, and allowing appropriate responses. They may help with the development of effective suicide prevention programs and enable timely evaluations of these programs in a manner that allows further refinements. These benefits may be felt at the local, regional, or country level.

\section{References}

Arensman, E. (2017). Suicide prevention in an international context. Crisis, 38(1), 1-6. https://doi.org/10.1027/0227-5910/a00 0461

Baran, A. (2020, November 19-20). Zwiększanie kompetencji studentów różnych kierunków w zakresie profilaktyki samobójstw - program ELLIPSE [Increasing the competences of students of various faculties in the field of suicide prevention - ELLIPSE program] [Paper presentation]. Second Suicidology Congress, Lodz, Poland. http://konferencjasuicydologiczna.umed.pl/wpcontent/uploads/2020/11/Suicydologia-abstrakt.pdf

Baran, A., Gmitrowicz, A., Koszewska, I., Makara-Studzińska, M., Ostaszewski, K., Palma, J., Parnowski, T., Pawelec, R., Rosa, K., Szafrański, T., Święcicki, Ł., \& Media Group at the Working Group on Prevention of Suicideand Depression at the Public Health Council of the Ministry of Health. (2018). Rola mediów w promocji zdrowia psychicznego i w zapobieganiu samobójstwo: m poradnik dla pracowników mediów [The role of media in mental health promotion and suicide prevention. Guide for media professionals]. https://suicydologia.org/wp-content/uploads/2016/09/Guide lines-for-media-professionals-on-suicide-PL-2.pdf

The Economist. (2021, July 13). Tracking covid-19 excess deaths across countries. The Economist. https://www.economist.com/ graphic-detail/coronavirus-excess-deaths-tracker

Knipe, D. W., Chang, S. S., Dawson, A., Eddleston, M., Konradsen, F. Metcalfe, C., \& Gunnell, D. (2017). Suicide prevention through means restriction: Impact of the 2008-2011 pesticide restrictions on suicide in Sri Lanka. PloS one, 12(3), e0172893. https:// doi.org/10.1371\%2Fjournal.pone.0172893

León-Cabrera, J., \& Kurmanaev, A. (2020, April 23). Ecuador's death toll during outbreak is among the worst in the world. The New York Times. https://www.nytimes.com/2020/04/23/world/ americas/ecuador-deaths-coronavirus.html 
Ministerio de Salud Pública (MSP). (2019). Manual "Capacitación para Cuidadores Comunitarios en prevención del suicidio" [Manual "Training for community caregivers in suicide prevention"]. https://aplicaciones.msp.gob.ec/salud/archivosdigitales/doc umentosDirecciones/dnn/archivos/AC_0342_2019\%2012\%20 ABRIL.pdf

Niederkrotenthaler, T., Braun, M., Pirkis, J., Till, B., Stack, S., Sinyor, M., Tran, U. S., Voracek, M., Cheng, Q., Arendt, F., Scherr, S., Yip, P. F. S., \& Spittal, M. J. (2020). Association between suicide reporting in the media and suicide: Systematic review and meta-analysis. BMJ, 368, m575. https://doi.org/10.1136/bmj.m575

Paz, C., Mascialino, G., Adana-Díaz, L., Rodríguez-Lorenzana, A., Simbaña-Rivera, K., Gómez Barreno, L., Troya, M., Paez, M. I., Cardenas, J., Gerstner, R. M., \& Ortiz-Prado, E. (2020). Anxiety and depression in patients with confirmed and suspected COVID-19 in Ecuador. Psychiatry and Clinical Neurosciences, 74(10), 554-555. https://doi.org/10.1111/pcn.13106

Pirkis, J., John, A., Shin, S., DelPozo-Banos, M., Arya, V., Analuisa-Aguilar, P., Appleby, L., Arensman, E., Bantjes, J., Baran, A., Bertolote, J. M., Borges, G., Brecic, P., Caine, E., Castelpietra, G., Chang, S.-S., Colchester, D., Crompton, D., Curkovic, M., ... Spittal, M. J. (2021). Suicide trends in the early months of the COVID-19 pandemic: An interrupted time-series analysis of preliminary data from 21 countries. The Lancet Psychiatry, 8(7), 579-588. https://doi.org/10.1016/S2215-0366(21)00091-2

Rosa, K. (2012). (Un)Reliability of statistics concerning suicidal behavior. The theoretical perspectives and social practice. Przeglad Socjologiczny, 61(2), 265-263.

Schwertner, J. (2020, February 3). Mitość w czasach zarazy [Love in the time of plague]. Retrieved August 31, 2021, from https:// wiadomosci.onet.pl/tylko-w-onecie/milosc-w-czasach-zara zy/nbqxxwm (available in English at https://www.european pressprize.com/article/love-in-the-time-of-plague/)

Thomas, K., Chang, S.-S., \& Gunnell, D. (2011). Suicide epidemics: The impact of newly emerging methods on overall suicide rates-a time trends study. BMC Public Health, 11, 314. https:// doi.org/10.1186/1471-2458-11-314

Torresano-Melo, M., Calles-López, J., \& García-Mejía, M. (Coord). (2018). La gestión de la información para la prevención del delito. El caso del Departamento de Análisis de Información del Delito (DAID) [The management of information for crime prevention. The case of the Department of Analysis of Crime Information]. https://publications.iadb.org/es/la-gestion-de-la-informa cion-para-la-prevencion-del-delito-el-caso-del-departamen to-de-analisis-de

Värnik, P., Sisask, M., Värnik, Arensman, E., Van Audenhove, C., van der Feltz-Cornelis, C. M., \& Hegerl, U. (2012). Validity of suicide statistics in Europe in relation to undetermined deaths: Developing the 2-20 benchmark. Injury Prevention, 18(5), 321-325. https://doi.org/10.1136/injuryprev-2011-040070

World Health Organization. (2021). Live life:An implementation guide for suicide prevention in countries. https://www.who.int/publica tions/i/item/9789240026629

Published online September 16, 2021

\section{Acknowledgments}

The authors would like to thank Isabela Troya, PhD, for her contributions and review of the Ecuador section.

\section{Funding}

Anna Baran is supported by the EU Erasmus+ Strategic Partnership Programme (grant number 2019-1-SE01-KA203-060571).

\section{Anna Baran}

Working Group on Prevention of Suicide and Depression at the Public Health Council of the Ministry of Health

Warsaw

Poland

annabaran00@gmail.com

Anna Baran, MD, PhD, MBA, is a chairperson of the media group at the Working Group on Suicide Prevention and Depression at the Public Health Council of the Ministry of Health, Poland. She is an international coordinator of the ELLIPSE-project cofunded by the Erasmus+ program of the European Union and a senior consultant psychiatrist and researcher at the Adult Psychiatry Department, Blekinge Hospital, Sweden. She is coauthor of Polish guidelines for media professionals and the guidelines for people who speak with the media and guide on postvention in schools. She is also cocreator of the Polish program for the prevention of suicidal behavior.

Michiko Ueda, PhD, is associate professor in the Faculty of Political Science and Economics at Waseda University in Tokyo, Japan. Prior to joining Waseda University, she taught at Syracuse University and California Institute of Technology. Her research interests include socioeconomic factors of suicide and media and suicide. She received her PhD from the Massachusetts Institute of Technology (MIT).

Rebekka Gerstner, MPH, MSc, worked for the Undersecretary of Health Services in the Ministry of Public Health of Ecuador until August 2021, where she took part in the construction of the inter-institutional strategy for suicide prevention, and participated in the process of elaborating and implementing several guidelines on suicide prevention and care for people with suicide intention or suicide attempts. She has collaborated on research on suicide in the COVID-19 context and has published several scientific articles on suicide and suicidality in Ecuador, particularly in the adolescents.

Agnieszka Gmitrowicz, MD, PhD, is a professor and head of the Department of Child \& Adolescent Psychiatry and of the Department of Psychiatry at the Medical University of Lodz, Poland. She is president of the scientific section of suicidology of the Polish Psychiatric Association, vice president of the Polish Suicidological Society, and chair of the Working Group on Prevention of Suicide and Depression at the Public Health Council of the Ministry of Health. She is also cocreator of the Polish program for the prevention of suicidal behavior. 